\title{
10. Process Solutions Day (PSD) der gfo
}

Die Gesellschaft für Organisation (gfo) wird am 28./29. April 2015 in Köln ihren zehnten Jubiläums „Process Solutions Day (PSD)“ veranstalten. Das ganzheitliche Prozessmanagement mit der daraus resultierenden Organisationsentwicklung und outputorientierten Unternehmenssteuerung wird immer mehr zum entscheidenden Wettbewerbsfaktor. Hierzu benötigen die Verantwortlichen die richtigen ProzessmanagementMethoden und -Tools sowie das Wissen über die neuen Entwicklungen und Business-Process-Management-Implementierungsstrategien.

Als neutrale und objektive Plattform stellt die Gesellschaft für Organisation den Rahmen für diese zweitägige Veranstaltung, die einen umfassenden Überblick über den derzeitigen
Stand der prozessorientierten Organisationsentwicklung mit BPM-Tool-Unterstützung gibt.

\section{Erfahrungen aus der Praxis}

Am ersten Tag findet das Anbieterforum mit der Präsentation und Ausstellung von 20 führenden Anbietern statt. Dieser Kongresstag endet mit einem Get-together zur weiteren Kontaktpflege. Am zweiten Tag berichten im Anwenderforum 14 Anwender aus unterschiedlichen Branchen über ihre Erfahrungen bei der BPM-Implementierung. Erwartet werden mehr als 200 Teilnehmer.

Weitere Informationen finden Sie unter www.psd2015.de

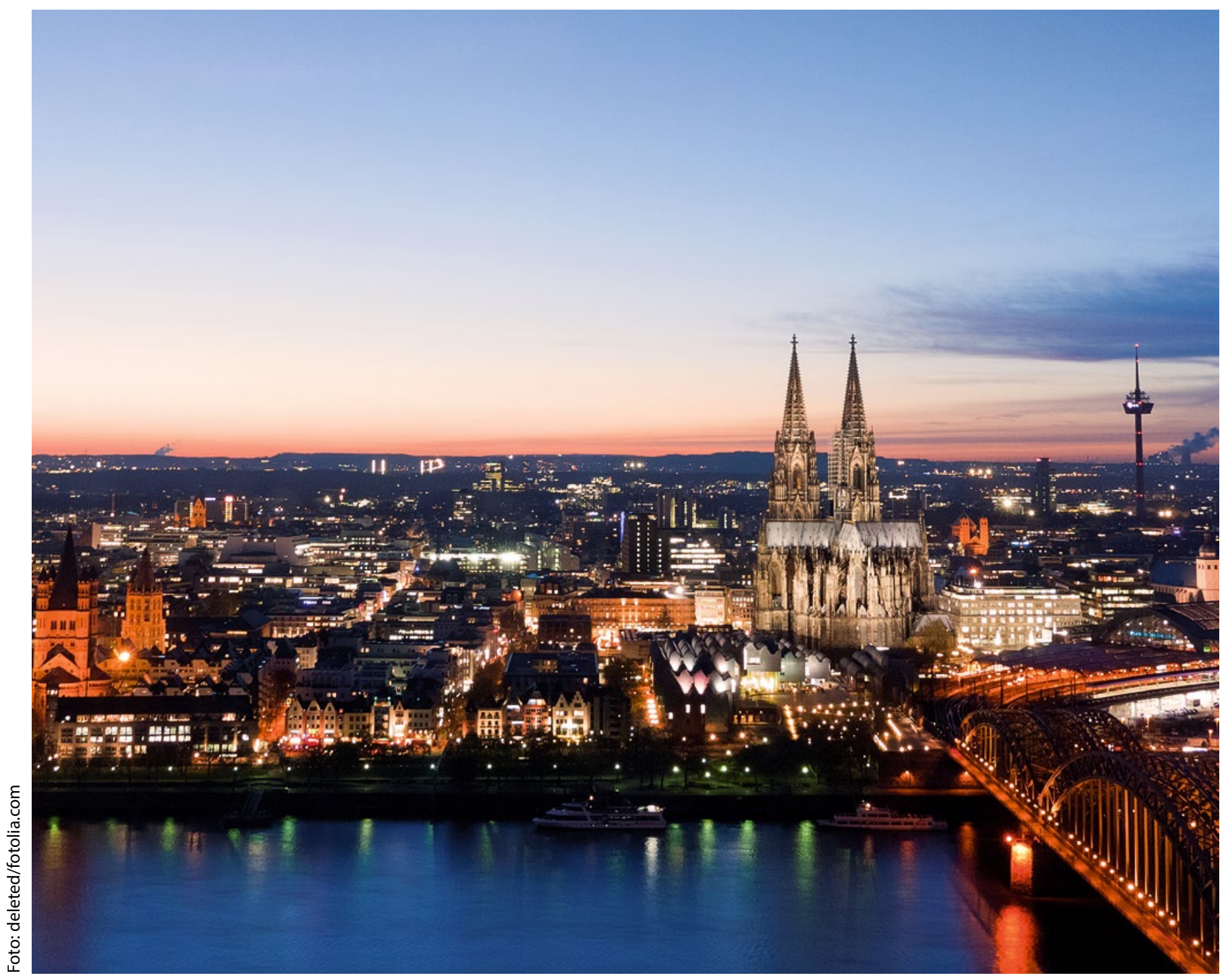

